\title{
Announcing a new partnership to promote personalized medicine
}

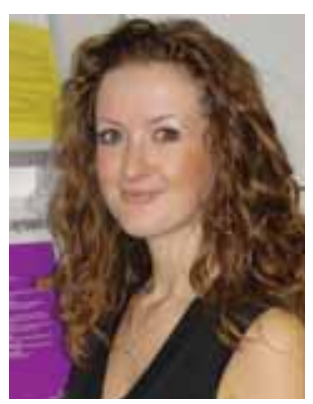

Elisa Manzoti

Editorial Director, Future M edicine Ltd, 1 Albert Place, London, N $310 \mathrm{~B}, \mathrm{UK}$ Tel.: +44 208371 6090; Fax: +44 208343 2313; E-mail: e.manzotti@ futuremedicine.com
M ost regular readers of our journal will be fully aware of the role and activities of the Personalized $M$ edicine Coalition (PMC). Those unfamiliar with the PM C can find a plethora of information about both the PMC and personalized medicine on the Coalition's website - www.personalizedmedicinecoalition.org. The PM C, an independent, non-profit group, seeks to advance the understanding and adoption of personalized medicine for the benefit of patients. Its diverse members, cutting across all of the stakeholders with an interest in personalized medicine, work together to educate opinion leaders and the public about the issues that will shape how personalized medicine develops, and how quickly everyone can benefit from it.

In this context, I'm pleased to report a new milestone in the development of Personalized M edicine. The journal has always enjoyed close links with the PM C, and we have appreciated PMC members' consistent support for the journal. The last issue, for example, included "Proposal for a new health record to support personalized, predictive, preventative and participatory medicine" by $Z$ Yoediono and R Snyderman of D uke University (N C, USA), and "From blockbuster medicine to personalized medicine" by JT Jorgensen of $D$ ako $D$ enmark $A / S$, both PM $C$ members.

In this issue, I'm delighted to announce formalization of the relationship between Personalized $M$ edicineand the PM C - future issues of the journal will feature a section of news and views directly from the PM C itself and selected articles published in the journal will al so feature on the Coalition's website. 0 ne designee within each member organization will also receive a one-year subscription to our journal.

Closer links can only benefit the dissemination of information regarding developments in pharmacogenomics and translational medicine, what those advances mean for the reality of personalized approaches to therapy, and also the associated sociopolitical and ethical implications that will condition progress in the field. We therefore believe that this is a very timely arrangement and represents a great opportunity to promote the Coalition, the journal, and the concept of personalized medicine itself, to the widest possible audience within the healthcare and health policy communities.

As we see more evidence of effective targeting of medicines to the most appropriate populations, the concepts underpinning personalized medicine are increasingly being embraced throughout the healthcare system. Against this backdrop, we look forward to working closely with the PM C in the future to provide objective and practical information about the scientific, medical, commercial, and policy issues associated with this new approach to medicine and healthcare delivery.

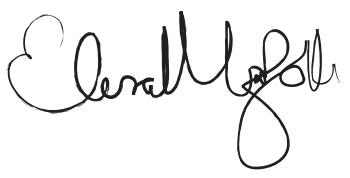

\section{ElisaManzoti}

Editorial D irector, Future M edicine 